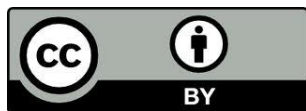

\title{
MANOEL DE MELLO: EXPOENTE NA RADIODIFUSÃO RELIGIOSA AO ANONIMATO NA HISTORIOGRAFIA BRASILEIRA
}

\author{
Manoel de Mello: Exponent In Broadcasting Religious But Anonymity in Brazilian
}

\author{
José Hélio de Lima \\ Teólogo graduado pela Universidade Metodista de São Paulo, Mestre em Ciências da Religião pela \\ Universidade Mackenzie de São Paulo e docente da FATEB Faculdade Telêmaco Borba, PR. \\ E-mail: prof.josehelio@gmail.com
}

\begin{abstract}
RESUMO: No estudo da historiografia dos movimentos religiosos brasileiros, constata-se que o catolicismo romano predominou por quase quatro séculos, e que foi no início do século XX que o monopólio foi quebrado quando ela deixou de ser a religião oficial do Estado, mas foi, sobretudo com o advento do protestantismo e, posteriormente, do pentecostalismo que outras formas de crenças cristãs passaram a ganhar espaço. Os evangélicos representam hoje quase um quarto da população nacional, e destes os pentecostais e neopentecostais somam mais de setenta por cento dos fieis. Até meados da década passada esses fieis eram ignorados como grupo ou segmento religioso nos livros de história brasileira utilizados nas escolas públicas e também nos centros de pesquisa da historiografia nacional. Alguns personagens importantes na formação das crenças e valores religiosos, como o Missionário Manoel de Mello, fundador da Igreja Pentecostal O Brasil Para Cristo, não deveriam estar fora dos principais textos, especialmente aqueles que narram os fenômenos religiosos modernos, como os midiáticos neopentecostais e católicos carismáticos. Diante destes fatos nesta pesquisa há uma proposta de levantar a questão observando algumas pesquisas que apontaram Mello como o personagem central do movimento denominado "pentecostalismo de rádio".
\end{abstract}

Palavras-chaves: Manoel de Mello; Pentecostalismo de Rádio; Igreja O Brasil Para Cristo.

ABSTRACT: In the historiography study about Brazilian religious movements is noted that Roman Catholicism prevailed for about four centuries, and that was in the beginning of XX century that the monopoly was broken when it ceased to be the official religion on the state, but was mainly with the advent of Protestantism, and later Pentecostalism that other Christian forms of beliefs began to get space. At the moment the Evangelicals represent about a quarter of the national population, and the Pentecostals and neo-Pentecostals add more than seventy percent of the believers. Until the middle of the last decade these believers were ignored as a religious group or segment in Brazilian history books used in public schools and also in the research centers at national historiography. Some important character in the beliefs formation and religious values, such as Manoel de Mello missionary, founder of The Brazil for Christ Pentecostal Church, should not be out of the main texts, especially those who describe the modern religious phenomenon, like the neo-Pentecostals and Catholic charismatics midiatics. Given these facts, in this research there is a proposal to raise the questions observing some researches that indicated Mello as the central character of the movement called "Pentecostalism in the radio."

Keywords: Manoel de Mello; Pentecostalism in the Radio; The Brazil for Christ Church 


\section{Intordução}

A exemplo de outros historiadores, que estudam os movimentos religiosos brasileiros e a relação estabelecida entre eles e a mídia de massas, a Dr ${ }^{a}$ Karina Kosicki Bellotti fez a seguinte constatação:

O uso da mídia e as estratégias de publicidade alteraram a dinâmica do campo religioso brasileiro a partir dos anos 1950, favorecendo principalmente o crescimento pentecostal. $\mathrm{O}$ veículo mais visado por grupos religiosos brasileiros era o rádio, seguido da televisão nos anos 1960 e 1970. (BELLOTTI, 2007, p.48)

Quando observadas as narrativas historiográficas do referido período, percebe-se que há alguns nomes que se destacam como personagens que contribuíram com a popularização do rádio entre os pentecostais, e, o Missionário Manoel de Mello, líder e fundador da Igreja O Brasil Para Cristo, como expoente do referido movimento. Entretanto, apesar das inovações e relevância nas ações de Mello nos trabalhos realizados são encontradas poucas informações acerca do referido personagem. O que existe nas mais diversas pesquisas, são sucintas menções e quase nenhum detalhe de como ocorreu todo o processo de transformação no modelo de comunicação pentecostal. Essa ausência de estudos específicos do período é explicada pelo historiador Tiago Watanabe ao observar que:

O encantamento das origens ou o bruit neopentecostal tem canalizado a energia dos estudiosos contemporâneos que preferem analisar a segunda metade do século XIX (os primeiros missionários, as primeiras igrejas e os primeiros colégios), ou, na história das organizações pentecostais e neopentecostais do final dos anos 1970. (WATANABE, 2011, p. 27)

O reflexo desse enfoque nos neopentecostais pode ser percebido pelos parcos trabalhos acadêmicos sobre os grupos caracterizados como os "pentecostais do rádio", que é o caso de Manoel de Mello ${ }^{1}$ e David Miranda.

\footnotetext{
${ }^{1}$ Manoel de Mello e Silva (1929-1990), nordestino da zona da mata do Pernambuco, que no final dos anos 40 migrou para cidade de São Paulo, onde se filiou a Igreja Assembleia de Deus; desligando-se da mesma em 1953, quando aderiu ao movimento americano denominado "Cruzada Nacional de Evangelização", ficando por lá até o fím de 1955. No início de 1956 fundou aquela que seria conhecida como a Igreja Evangélica Pentecostal O Brasil Para Cristo, cujo principal diferencial das demais
} 
A proposta dessa pesquisa é levantar alguns fatos envolvendo Manoel de Mello, que foram abordados e registrados em determinados trabalhos realizados por pesquisadores, e buscar conhecer as eventuais causas que levam a ausência de registros de sua pessoa na historiografia brasileira. Para tanto, iremos analisar algumas pesquisas cujo objeto de estudo tenha sido o pentecostalismo dos anos 50 a 70, que usaram a mídia rádio para visibilizar o movimento e arrebanhar novos adeptos.

\section{Registros entre os anos de 1965 a 2011}

Apesar das primeiras comunidades pentecostais brasileiras terem se estabelecido na primeira década do século XX, somente se transformaram em objeto de estudo quatro décadas depois. Deve-se a essa falta de trabalhos científicos acerca do assunto, entre outros fatores, o número inexpressível de adeptos a esse segmento religioso, haja vista que em 1950 os evangélicos ${ }^{2}$ representavam apenas 3,35\% (três por cento) da população brasileira. (LOPES JÚNIOR, 1998, p.3)

Entretanto, pode-se observar que a partir do momento que alguns líderes saíram do anonimato e proporcionaram visibilidade a seus grupos, sobretudo usando a mídia rádio, eles não apenas cresceram numericamente como passaram a ocupar um espaço que até então era reduto católico. O que chamou a atenção de alguns pesquisadores dos fenômenos sociais, levando-os a desenvolver trabalhos científicos voltados para os referidos grupos.

Nos parágrafos seguintes será feito alguns recortes de pesquisas que estão sendo desenvolvidas desde o início dos anos 60, quando o líder pentecostal Manoel de Mello se tornou o centro das atenções graças ao modelo que empregou no processo de proselitismo, que tinha em programas radiofônicos um meio de evangelismo. Contudo, apesar de ter sido o principal nome do "radio evangelismo" brasileiro entre os anos $50 \mathrm{e}$ 70 estabelecendo uma nova modalidade de comunicação entre os pentecostais, Mello e a Igreja O Brasil Para Cristo, até 2008 não haviam sido objetos de estudos específicos

denominações pentecostais da época era a presença diária em programação radiofônica, a partir da cidade de São Paulo.

${ }^{2}$ Nesta pesquisa são identificados como "evangélicos" tanto os membros das denominações protestantes históricas (Presbiterianos, Metodistas, Anglicanos, Batistas, Luteranos e Congregacionais) como os pentecostais (Congregação Cristã do Brasil e Assembléia de Deus). 
nos meios acadêmicos brasileiros, o que tem feito com que sua relevância no cenário brasileiro caía no esquecimento.

$\mathrm{O}$ que se constatou nas pesquisas envolvendo os mais diversos grupos religiosos brasileiros e o uso da mídia de massas é que eles mencionam Manoel de Mello e os novos paradigmas que ele instituiu, a partir do rádio. Entretanto a medida que Mello saiu de cena e surgiram novas modalidade de comunicação, com ascensão do neopentecostalismo, os empreendimentos melleanos, que serviu de marco para os novos grupos, tem sido cada vez menos lembrados. Para analisarmos como isso acontece, observaremos algumas obras que tratam do comportamento dos pentecostais brasileiros, cuja presença na mídia deu visibilidade ao grupo, seguindo o modelo estabelecido por Manoel de Mello em meados dos anos 50, mas principalmente como um personagem como ele deixa de ser ator principal para entrar no anonimato historiográfico.

\subsection{William R. Read (1967)}

No ano de 1967 a Imprensa Metodista lançou em português o livro do pesquisador presbiteriano William Read, que destina parte de seus estudos para destacar o papel de Manoel de Mello e as mudanças que ele estava promovendo no campo religioso brasileiro no início dos anos 60. Estudioso dos fenômenos religiosos na América Latina, ao perlustrar o rápido crescimento dos pentecostais no Brasil entre as décadas de $50 \mathrm{e}$ 60, deixou registrado em sua obra uma percepção protestante do referidos grupos. Cabe mencionar que, atualmente, é a principal fonte de embasamento teórico sobre Mello e mídia pentecostal neste período, por retratar os acontecimentos envolvendo o missionário pernambucano e seus pares em tempo real, vez que Read estudou o assunto enquanto ele estava acontecendo. O texto a seguir demonstra a sua leitura acerca do modelo e práticas de Mello.

Seu programa de rádio, apela aos brasileiros. Em meados da década de 1950, começou ele a fazer experiência com um programa de rádio, matinal. Seu modo popular e rústico alcançou êxito entre grande número de ouvintes dos lugares mais longínquos. Utilizou-se do tipo de música evangélica, popular no interior brasileiro, de ritmo marcado com os pés, pregando uma mensagem evangélica simples e clara. $\mathrm{O}$ rádio tornou-se a voz do Missionário, para anunciar suas campanhas, reuniões e cruzadas por todo o Brasil. Bastava anunciar no rádio 
que o missionário Manoel de Melo (sic) estaria em determinada cidade, em tal lugar a tal hora, isso era suficiente para garantir a reunião de grande massa popular. Diferentes cruzadas foram assim divulgadas, obtendo os mesmos resultados — grandes multidões aguardavam a chegada do dinâmico pernambucano, para vê-lo e ouvi-lo. Anunciavam-se curas miraculosas pelo rádio, e por esse meio também faziam-se orações pelos casos difíceis. (READ, 1967, p. 150)

Como naqueles dias o uso do rádio por pentecostais não era comum, a presença de Mello nas emissoras paulistas América e Tupi não apenas deu visibilidade a ele como também a sua igreja, tornando os cultos uma atração. Segundo Read ele havia desenvolvido um estilo próprio de apresentação e, apesar do regime de exceção estabelecido pelo governo militar da época, sugestionava em questões políticas.

Programa de rádio e ministério, que aumentam sua popularidade. $\mathrm{O}$ rádio constitui-se num dos meios pelo qual o "Brasil para Cristo" conseguiu assegurar um número tão grande de adeptos. Segundo estimativa de Manoel de Melo, o número de ouvintes de seu programa de rádio, em todo o país, sao é de cinco milhões. A estação de rádio, de que se utiliza em São Paulo é das mais poderosas do paíis, possuindo um número de frequiências de ondas curtas, que alcançam o mundo todo. O missionário não gosta de preparar seus programas radiofônicos com antecedência, gravando-os; prefere estar presente tôdas as manhãs, às 6 horas, para uma apresentação "ao vivo". Seu programa não tem nada de elaborado, é feito com tôda a naturalidade. Apresenta músicas evangélicas, do tipo mais popular. Os números vocais são acompanhados por violão ou acordeão, com muito rítmo. Manoel de Melo toma corno objeto de suas programacões, acontecimentos recentes, fatos politicos, escândalos nacionais, e outros temas realizam uma típica cruzada Manoel de Melo. Éle não tem mêdo de entrar no campo da Política para denunciar atos sórdidos, expondo-os, citando nomes e clamando por reformas. E assim prossegue, mostrando que, não obstante, o caminho do Evangelho constitui-se na melhor e única solução. (READ, 1967, p. 153-4)

Manoel de Mello não apenas opinava em questões políticas como tinha um projeto arrojado para os anos seguintes, o que acabou não acontecendo. Relata Read:

Seu plano político para um futuro imediato visa a eleição do viceprefeito da cidade de São Paulo, em 1965. Pretende eleger um senador federal para tomar o lugar de certo Padre Calazans que, por sua vez, pretende reeleger-se em 1965. Por volta de 1970, espera eleger para vice-presidente da República um evangélico. (READ, 1967, p. 159).

2.2. Beatriz Muniz de Souza (1969) 
Outra fonte de pesquisa importante, que aborda as questões envolvendo os pentecostais brasileiros das décadas de 50 e 60 é o livro escrito pela socióloga Beatriz Muniz de Souza, resultado das investigações que realizou para a elaboração de sua tese de doutorado, defendida na Universidade Estadual de Campinas, SP. ${ }^{3}$ Como este grupo se tratava de um grupo emergente ou uma nova modalidade de pentecostalismo, havia poucas obras que tratava do assunto e diante disso ela teve que fazer pesquisas de campo participando de cultos, entrevistando fiéis e líderes dos diversos grupos. Na ocasião ela fez as seguintes constatações acerca de Manoel de Mello e sua igreja, dizendo que:

Através dos meios de comunicação fortemente empregados pela organização religiosa, sua atual expansão se faz sentir em vários setores: Programas diários pelo rádio; reuniões mensais em grande cinema da Capital; concentrações em praças púbicas para comemorar datas nacionais e religiosas; intenso trabalho de assistência social; construção do "maior templo evangélico do mundo", com capacidade para 25.000 pessoas. (SOUZA, 1969, p. 42)

Souza ainda confirma que a participação direta da Igreja O Brasil Para Cristo na política partidária - onde o principal cabo eleitoral era o Missionário Mello - resultou na eleição e reeleição do pastor Levy Tavares para Deputado Federal ${ }^{4}$ nos anos 60 e, do também pastor Geraldino dos Santos para vereador na cidade de São Paulo, que no pleito seguinte deixou a Câmara Municipal para assumir o mandato de Deputado Estadual, todos com expressiva votação (SOUZA, 1969, p. 45);

A socióloga Beatriz reportou ainda que as inovações implementadas por Mello em meados dos anos 50, tanto no campo religioso como social, serviram de modelo para novos grupos que surgiram nos anos 60, conforme sua narrativa: Grandes concentrações são organizadas, especialmente pelos movimentos mais novos dentro do

\footnotetext{
${ }^{3}$ Leonildo Silveira Campos afirma que este é o primeiro texto acadêmico publicado no Brasil que retrata um estudo sobre o pentecostalismo brasileiro, por isso tornou-se o marco teórico pioneiro e mesmo havendo passado mais de trinta anos continua sendo citação obrigatória nos estudos sobre o pentecostalismo. (CAMPOS, 1997, p. 37)

4 "Fazendo da credibilidade religiosa um instrumento de persuasão dos fiéis, Mello conseguiu a façanha de eleger Levy Tavares como o primeiro Deputado Federal de igreja pentecostal da história da política brasileira, 18 tornando-se o legislador mais novo, com apenas 26 anos de idade e o quinto mais votado de São Paulo pelo Partido Social Democrático (PSD).” (LIMA, 2009).
} 
Pentecostalismo, adotando-se, quase sempre, o estilo de orientação propugnado pela Igreja 'O Brasil para Cristo"' (SOUZA, 1969, p. 118).

\subsection{Walter Hollenweger (1976)}

Nos anos 70 Mello ainda continuava em evidência não apenas pelas inovações midiáticas - agora comuns entre os pentecostais - mas, pelo engajamento nos movimentos sociais, ecumênicos e defesa da liberdade política, com frequentes críticas ao regime militar implantado no Brasil. Será que isso não é um mito?

Em pesquisas recentes constatamos que Mello foi detido algumas vezes pela policia e levado ao DOPS ${ }^{5}$ para prestar esclarecimentos acerca de assuntos que tratava em seu rotineiro programa de rádio.

Pesquisadores, como Paul Freston, atribuem a interesses pessoais e articulações políticas fatos como a filiação da Igreja O Brasil Para Cristo ao Conselho Mundial de Igrejas (CMI) e a participação de Mello na fundação da CESE - Coordenadoria Ecumênica de Serviço, ${ }^{6}$ pois na ótica do sociólogo tudo teria sido uma forma de receber proteção internacional contra retaliações que poderia sofrer por criticar a ditadura militar brasileira e ser beneficiado com verbas para projetos sociais de sua igreja (FRESTON, 1993, p. 91). Sejam quais forem as motivações, tanto Manoel de Mello quanto a Igreja o Brasil Para Cristo tinham suas ações repercutindo fora do país, basta ver o que constatou o teólogo e professor suíço Walter Jacob Hollenweger:

\footnotetext{
${ }^{5}$ O DOPS - Departamento de Ordem Política e Social foi o órgão do governo brasileiro criado durante o Estado Novo, cujo objetivo era controlar e reprimir movimentos políticos e sociais contrários ao regime no poder.

6 “Criada em 1973, com o objetivo de fortalecer os grupos e organizações populares, nas suas lutas por transformações políticas, econômicas e sociais, a CESE já apoiou, com recursos técnicos e financeiros, mais de 6,5 mil iniciativas populares, em todo o Brasil, melhorando a qualidade de vida de mais de 6,1 milhões de pessoas. A CESE surge no momento histórico em que agências de cooperação internacional, Igrejas, movimentos sociais e organismos ecumênicos passam a discutir os rumos da cooperação internacional no Brasil, até então voltada para a realização de grandes projetos. Em 1972, a consulta Ajuda Inter-eclesiástica para o Norte-Nordeste do Brasil, realizada em Salvador, sob o estímulo do Conselho Mundial de Igrejas, reuniu as denominações: Episcopal do Brasil, Metodista, Evangélica de Confissão Luterana no Brasil, Missão Presbiteriana do Brasil Central, Cristã Reformada do Brasil, Evangélica Pentecostal 'O Brasil para Cristo' e Igreja Católica (representada por intermédio da CNBB). A partir desta discussão, foi aprofundado o conceito de 'pequeno projeto' - pontual, sem relação de dependência e que criasse as condições para o fortalecimento das organizações populares, atuando como semente de suas ações. A opção pelo enfoque de apoio ao Norte e Nordeste do país também ficou explicitada nos documentos resultantes da consulta e que orientaram os critérios de atuação da nova entidade que ali nascia." (In LIMA, 2009, p.149)
} 
(...) La organización más importante es la Igreja Evangélica Pentecostal 'Brasil para Cristo', dirigida por el famoso evangelista Manuel de Melo. El luterano Meyer escribe: 'Sin duda alguna es uno de los personajes eclesiásticos más importantes del Brasil'. 'Desde Pernambuco, donde actuaba como pastor en la Assembléia de Deus, se dirigió a San Pablo. Después de algunos años se separó de las Assembléias y ofreció su talento excepcional de evangelista, su famosa capacidad oratoria y.' (HOLLENWEGER, p. 149)

Exageros a parte, Hollenweger aponta Manoel de Mello como um líder pentecostal influente e de vanguarda, principalmente pelo seu envolvimento nos movimentos ecumênicos, porque apesar de naquele momento liderar umas das mais importantes igrejas evangélicas brasileiras, não se omitia do papel social e atuava em prol da democracia no país, pois isso não era comum entre os seus consortes das igrejas pentecostais (HOLLENWEGER, p. 151).

\subsection{Paul Freston (1993)}

Depois da socióloga Beatriz Muniz de Souza que fez um trabalho baseado em pesquisas in loco nos anos 60, foi outro sociólogo que voltou os olhos para os acontecimentos envolvendo os pentecostais brasileiros dos anos 50 e 60, desta vez é o inglês Paul Freston que vai analisar o papel dos pentecostais entre os demais evangélicos brasileiro na política, preenchendo um hiato cientifico em torno do tema Manoel de Mello ou Igreja O Brasil Para Cristo, pelo menos em perspectiva sociológica. Razão pela qual é comum encontrarmos a obra de Freston nas bibliografias dos mais diversos trabalhos realizados sobre os evangélicos.

Freston, porém, apresenta um cenário que foi construído não apenas em duas, mas no transcorrer de sete décadas onde os evangélicos figuraram na política nacional. Ele enfatiza a meteórica ascensão do líder pernambucano nas seguintes palavras:

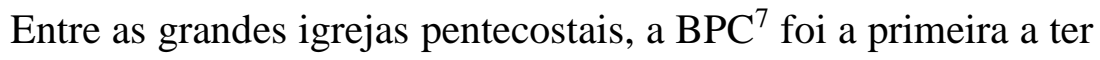
fundador brasileiro, a eleger políticos e a relacionar-se com entidades ecumênicas. Foi a sensação religiosa dos anos 50 e 60. Enquanto o país vencia 50 anos em cinco, um operário nordestino em São Paulo sintetizava o espírito nacionalista e popular, construindo um império religioso autônomo jamais

\footnotetext{
${ }^{7}$ BPC - sigla utilizada pelo sociólogo para identificar "Igreja O Brasil Para Cristo".
} 
visto até então no Brasil. Mas não durou. (FRESTON, 1993, p. 86)

Quanto à participação de Mello na política partidária, Freston observa ainda que "O migrante nordestino percebeu que a própria cultura política da metrópole em explosão podia encontrar um equivalente religioso, como também que os políticos populistas precisavam abrir espaços em suas clientelas para os líderes do novo protestantismo popular.” (1993, p. 88). Seja na política, nos meios utilizados para cultos ou uso mídia de massas, como o rádio e televisão, o sociólogo observa que foi Mello um inovador pentecostal que precedeu em pelo menos duas décadas os avanços dos outros segmentos dos evangélicos brasileiros.

\subsection{Leonildo Silveira Campos (1997)}

Em uma abordagem sobre o surgimento e expansão da Igreja Universal do Reino de Deus, o cientista da religião Dr. Leonildo Silveira Campos ao construir o ambiente no qual_teve início o uso da mídia de massas pelos pentecostais brasileiros, faz menção ao papel exercido por Manoel de Mello no processo de elaboração de uma igreja votada para o rádio como meio de transmissão de mensagens religiosas. Depois da narrativa de como Mello iniciou as atividades radiofônicas, bem como o êxito alcançado com sua proposta de pregação de cura divina por meio do rádio, Campos fez as seguintes observações:

O sucesso de Melo (sic) pode ser explicado, entre outras coisas, pelas suas pregações radiofônicas, que provocava uma inteiração espiritual entre o locutor e o ouvinte, capaz até de resultar em cura divina e milagres por intermédio do rádio, o que, aliás, era uma prática comum entre os adeptos de cura divina nos Estados Unidos. (CAMPOS, 1997, p. 271)

Ressalta ainda que, Mello por ser o líder pentecostal mais influente nos anos 60 fez escola, principalmente com o modelo de mensagem e meios empregados na expansão de sua igreja. Entre os que seguiram seus rastros, pelo menos no modelo de mensagens e forma de difusão, está o fundador da Igreja Deus é Amor, David Martins Miranda. (CAMPOS, 1997, p. 272-3)

\subsection{Brenda Maribel Carranza Davila (2005)}


Em pesquisa intitulada "Os movimentos do catolicismo brasileiro", a cientista social Dr ${ }^{\mathrm{a}}$ Brenda Maribel Carranza Davila, para tratar do ambiente religioso que influenciou as mudanças no modelo de comunicação do catolicismo brasileiro, recorreu a fatos envolvendo personagens que contribuíram formação do catolicismo midiático moderno. Ao observar o cenário entre os pentecostais teceu os seguintes comentários:

Até os anos 50, os pentecostais não tinham espaço significativo no rádio brasileiro, ora por falta de recursos, ora por pressões católicas. O processo para se inserir foi lento, começou com o aluguel de espaços em horários noturnos e menos nobres, para logo comprar suas próprias emissoras. Manoel de Melo (sic) ex-pregador da Assembléia de Deus - será o primeiro, em 1955, com o programa a Voz do Brasil para Cristo, na Rádio América e logo na Rádio Tupi (2005, p. 214)

Devemos observar que, não há como abordar a relação entre alguns grupos católicos e o rádio sem obrigatoriamente aludir o personagem Manoel de Mello. Se a informação que ela tinha a levando afirmar que Mello foi o primeiro pentecostal no rádio, pode ser passiva de questionamento, em contrapartida, o papel que Mello desempenhou na inserção dos pentecostais no processo de comunicação radiofônico é incontestável. Não é possível abordar religião e rádio omitindo o papel desempenhado pelo líder pernambucano.

Quando a professora Brenda Maribel, trata posteriormente dos agentes influenciadores do catolicismo relata que, entre outros, Mello e o modelo de programa serviram de referencial para o novo empreendimento comunicacional da igreja da Santa Sé.

Paralela a essa presença pentecostal protestante, o catolicismo passa a adotar outro modelo comunicacional com as missões populares, pregando a conversão pessoal, a vida sacramental e a regulamentação doutrinal. No centro desse processo estará a retomada do laicato que será inserido na organização eclesial, centrando-se na sua formação e educação. Nesse contexto o rádio será o centro de uma nova dimensão educativa, promovendo uma inserção popular com a proposta de formação de lideranças cristãs. (2005, p. 215)

À medida que o tempo vai passando e novos atores vão surgindo no cenário religioso nacional percebe-se nitidamente que, aqueles que fizeram parte do processo alterador do modelo de comunicação vão caindo no esquecimento, pois deixam de 
ocupar "longos espaços" para aparecer esporadicamente em "resumidos parágrafos" nos textos acadêmicos.

\subsection{Karina Kosicki Bellotti (2007)}

No universo dos pesquisadores dos fenômenos religiosos brasileiros; sobretudo aqueles que envolvem os pentecostais, suas presenças na mídia de massas, e as alterações que estão promovendo no modelo de fé nacional; encontramos a historiadora Dr $^{\mathrm{a}}$ Karina Bellotti. Entre outros trabalhos realizados por ela está aquele cujo título é: "Delas é o reino dos céus", no qual a historiadora analisa a contribuição da mídia na formação das crianças evangélicas brasileiras. No referido trabalho ela faz a seguinte observação: "Dois fatos marcaram a presença evangélica no Brasil nos anos 1950: a vinda da Cruzada Nacional de Evangelização, fundada pelo missionário americano Harold Williams, e o avivamento em igrejas protestantes.” (BELLOTTI, 2007, p. 71).

A professora Karina também constatou que o envolvimento dos pentecostais com a mídia de massas foi um dos elementos que contribuiu para o crescimento dos grupos entre as décadas de 50 e 60, entretanto ela ressalta que fatores de ordem social, bem como uma proposta religiosa de inclusão e socorro a pessoas desassistidas pelo Estado, também foram fundamentais para que a proposta apresentada pelos pentecostais encontrasse guarida, sobremaneira entre os moradores dos centros urbanos. (BELLOTTI, 2007, p. 71-2).

A Igreja do Evangelho Quadrangular, O Brasil para Cristo, Igreja do Nazareno, Igreja de Nova Vida e Igreja Pentecostal Deus é Amor, investiram em estratégias de propaganda que incluíram o uso de rádio para anunciar campanhas e cruzadas, distribuição massiva de folhetos de eventos, campanhas e correntes para envolver os fiéis em atividades contínuas nas igrejas, em batalhas espirituais contra os "demônios" do catolicismo, do candomblé, do espiritismo, da pobreza e da doença. (BELLOTTI, 2007, p. 72).

Seguindo um modelo de abordagem sociológica também presente nas considerações realizadas pelo sociólogo Ricardo Mariano, (1997) a Dr ${ }^{\mathrm{a}}$ Karina ressalta a contribuição que os missionários americanos Harold William e Raymond Boatright, da Igreja do Evangelho Quadrangular, deram ao pentecostalismo brasileiro estabelecendo 
um novo modelo litúrgico e de proselitismo. Foram esses missionários que influenciaram Manoel de Mello, que depois de ter sido desligado da Igreja Assembléia de Deus juntou-se a eles.

As primeiras experiências de Manoel de Mello com pregação de cura divina e uso do rádio se deram em cruzadas evangelísticas empreendidas e organizadas pelos líderes da Cruzada Nacional de Evangelização, que posteriormente adotou o nome da matriz americana (Igreja do Evangelho Quadrangular), conforme constatou a $\operatorname{Dr}^{\mathrm{a}}$ Karina. Todavia, essa relação durou pouco mais de um ano, até que o Missionário Manoel de Mello decidiu fazer seus próprios empreendimentos. Pondo em prática os conhecimentos adquiridos com os líderes da Cruzada, logo comprou horário na Rádio Piratininga de São Paulo de onde passou a apresentar diariamente o Programa A Voz do Brasil Para Cristo, tornando-o mais popular que os seus mentores americanos, segundo a verificação de Freston (1993).

Cabe aqui uma ressalva. De acordo com os principais pesquisadores do pentecostalismo brasileiro dessa época, apesar dos missionários americanos da Cruzada terem implantado o movimento de cura divina e incentivado o uso do rádio pelos pentecostais brasileiros, foi Manoel de Mello que soube tirar proveito deste modelo, sobretudo porque não apenas usava o rádio esporadicamente para promover os eventos por ele realizados, assim como faziam os líderes da Cruzada, mas também porque alugou um horário fixo no qual mantinha uma programação diária e variada. Portanto, o modelo americano de evangelismo tomou forma nas ações do pernambucano Mello.

\subsection{Tiago Hideo Barbosa Watanabe (2011)}

Entre os trabalhos acadêmicos mais recentes que aborda temas envolvendo os evangélicos brasileiros, está a tese de doutorado elaborada e defendida pelo historiador Tiago Hideo Barbosa Watanabe, cujo título é "Escrito nas fronteiras". Apesar de o enfoque ser as denominações históricas que se estabeleceram no Brasil em meados do Século XIX, o Dr. Watanabe narra alguns fatos envolvendo os pentecostais, sobretudo quando aborda a questão envolvendo o crescimento das igrejas históricas. Disse ele:

Em termos numéricos, as igrejas evangélicas tradicionais cresciam a um ritmo menor (ritmo de crescimento que acompanhava o crescimento vegetativo da população) enquanto 
os pentecostais apresentavam um crescimento superior a $100 \%$ ao ano a partir dos anos 1970. Os grupos pentecostais mais antigos como a Assembléia de Deus (1911) e Congregação Cristã (1910) e as novas igrejas como a Igreja do Evangelho Quadrangular (1952), a Igreja Evangélica Pentecostal "O Brasil para Cristo" (1956) e a "Deus é Amor" (1962) cresciam. (WATANABE, 2011, p. 137)

Watanabe constatou que na década de 60 a Igreja O Brasil Para Cristo figurava entre as cinco igrejas pentecostais mais importantes do país, pelo menos a mais evidenciada. Ele descreve a receita do sucesso das igrejas "pentecostais do rádio" ou de "cura divina", da seguinte maneira:

A sociedade brasileira presenciou o crescimento evangélico de variadas formas: as lonas de circo itinerantes da Cruzada Nacional prometiam a cura divina; pastores como Manoel de Melo (sic) emitiam bênçãos e curas nas emissões de rádio; templos evangélicos com nomes como "O Brasil para Cristo" e "Deus é amor" se espalhavam em locais de grande movimentação (primeiramente em bairros operários para posteriormente regiões centrais) e, principalmente, o número de evangélicos dispostos a oferecerem a seus amigos e familiares "soluções para problemas cotidianos" era grande. (WATANABE, 2011, p. 139)

Ainda que a pesquisa não seja especificamente sobre os pentecostais, onde se incluiria Manoel de Mello, a menção desse personagem nos estudos sobre os movimentos religiosos dos anos 50 a 70, especialmente os que usaram o rádio para promover cultos e programações de suas igrejas, tornara-se inevitável. Não pela dimensão de sua igreja na atualidade, pois hoje a Igreja O Brasil Para Cristo é apenas uma denominação mediana, mas pelas mudanças que ela estabeleceu no construto religioso nacional, seja através do modelo litúrgico ou uso sistemático da mídia rádio no processo de expansão do movimento.

\section{Considerações Finais}

Como se pode aludir no texto, a presença de Manoel de Mello no cenário religioso brasileiro naquele momento foi marcada por ações que deu a ele visibilidade nacional e o tornou um modelo para novos líderes que foram surgindo naqueles dias. Entre as alterações promovidas por Mello no construto religioso brasileiro estão: o modelo de 
programa radiofônico que ele implantou; o uso de espaços públicos para cultos, como praça de esportes, cinemas e teatros, considerados profanos pelos seus pares evangélicos; a implantação de igrejas em todos os estados da federação a partir o programa A Voz do Brasil para Cristo; o engajamento na política partidária, elegendo o primeiro Deputado Federal de uma igreja pentecostal; a adesão a movimentos ecumênicos, como o CMI; assim como a construção de um "mega templo" em uma região de classe média paulistana. Portanto foi um personagem importante na construção do pentecostalismo nacional. A questão é: Por que não há estudos específicos sobre Mello entre os historiadores brasileiros?

Em síntese, perlustra-se que, apesar da indiscutível contribuição que Manoel de Mello deu ao pentecostalismo nacional, independentemente de suas motivações, até o momento não há registros detalhados na historiografia brasileira que tenha sido resultado de investigação científica. Até o ano 2008 não havia nenhum trabalho acadêmico que tivesse estudado especificamente as ações de Manoel de Mello e sua igreja. O trabalho que tratar desse fragmento histórico é a dissertação de mestrado que se deu no Programa de Pós-Graduação em Ciências da Religião da Universidade Presbiteriana Mackenzie de São Paulo, realizado por este pesquisador que é teólogo e membro da igreja fundada por Mello. Por fim, será que não há conteúdo histórico relevante que precise ser narrado pela academia de história brasileira? A historiografia brasileira não estaria omitindo em suas narrativas um fato tão importante envolvendo a religiosidade nacional, contribuindo para que acontecimentos como estes sejam esquecido por falta de registros?

\section{Referenciais}

BELlOTTI, Karina Kosicki. Delas é o reino dos céus: mídia evangélica infantil na cultura pós-moderna do Brasil (anos 1950 a 2000) - Campinas, SP: [s. n.], 2007,

CAMPOS, Leonildo Silveira. Teatro, templo e mercado: organização e marketing de um empreendimento neopentecostal. Petrópolis, RJ: Ed. Vozes, 1997. 
CARRANZA DÁVILA, Brenda Maribel. Movimentos do catolicismo brasileiro: cultura, mídia, instituição. Tese (Doutorado em Ciências Sociais) - Universidade Estadual de Campinas: Campinas, SP, 2005.

FRESTON, PAUL. Protestantes e política no Brasil: da constituinte ao impeachment. 1993. Tese (Doutorado em Ciências Sociais) - Universidade Estadual de Campinas, Campinas, SP, 1993.

HOLLENWEGER, Walter. El pentecostalismo: historia y doctrinas. Buenos Aires. Editorial La Aurora, 1976.

MARIANO, Ricardo. Neopentecostais: sociologia do novo pentecostalismo no Brasil. São Paulo: Loyola, 1997.

LIMA, José Hélio de. Manoel de Mello \& Rádio: história da organização e expansão da Igreja O Brasil para Cristo. Hortolândia, SP: Foco Editorial, 2009).

LOPES JÚNIOR, Orivaldo P. O protestantismo no nordeste do Brasil. In Anuário Estatístico da FIBGE. Departamento de Ciências Sociais da Universidade Federal do Rio Grande do Norte - UFRN, 1998, p. 3.

READ, William R. Fermento religioso nas massas do Brasil. São Bernardo do Campo, SP. Imprensa Metodista, 1967.

SOUZA, Beatriz Muniz. A experiência da Salvação: pentecostais de São Paulo. São Paulo: Editora Duas Cidades, 1969.

WATANABE, Tiago Hideo Barbosa. Escritos nas fronteiras: os livros de história do protestantismo brasileiro. Tese (Doutorado) - Universidade Estadual Paulista. Faculdade de Ciências e Letras, Assis, 2011, p. 27.

Recebido: 17/09/2012

Received: 09/17/2012

Aprovado: 28/11/2012

Approved: $11 / 28 / 2012$ 